\title{
The perception of satisfaction with virtual social networks: A comparative analysis
}

\author{
Javier A. Sánchez Torres" and Francisco-Javier Arroyo-Cañada \\ Universitat de Barcelona
}

\begin{abstract}
The main aim was to determine the level of satisfaction of users of Facebook, Twitter, and Instagram by comparing the concept of a "virtual social network" with the perception of use by the users from the subjective evaluation of five features.

An empirical study was realized with users of social networks in Latin America by measuring similar features - customization, interactivity, multimedia, privacy, and regulation - which are the features that are the most discussed in the literature. The analysis of the information was conducted with the Hamming distance.

This study presents a new assessment of satisfaction with virtual social networks by taking into account features that had not previously been considered as a group; furthermore, no differences in perceptions by gender or age were found and the virtual social network with the best assessment was identified as Twitter.
\end{abstract}

Keywords: Internet, behaviour, consumers, social networks.

JEL codes: M31, M37, M39.

\section{Introduction}

A virtual social network can be defined as a scenario for social interaction involving a dynamic exchange between people on the Web, which is characterized by groups with the same needs or problems (Parra-Castrillón, 2010).

\footnotetext{
" Corresponding author. Email: jsanchto19.alumnes@ub.edu
}

ISSN 0212-1867 / e-ISSN 1989-3558

(C) ESIC Editorial, ESIC Business \& Marketing School

DOI: $10.7200 /$ esicm.153.0471.4i

http://www.esic.edu/esicmarket 
Companies like Facebook, Twitter, and Instagram, offering services for online social networks, are popular worldwide. Their use has increased exponentially, generating a change in the dynamics of human communication and socialization in the twenty-first century and allowing comfortable and instant interaction. Their development has involved offering many services to their customers, such as customization, allowing them to position themselves as the preferred tools for communication between people (Park, 2014).

Virtual social networks have other features that are important to their users. On the one hand, technological development has enabled them to have more media tools, allowing higher levels of multimediality, that is, the ability to deliver audio, video, 3D games, and so on (Chan, Cheung, Shi, and Lee, 2014). However, users of virtual social networks are subject to conditions and policies for managing their information, creating a network in which information is managed and stored privately, causing problems of privacy, safety, and regulations to arise.

At present, few studies exist on virtual social networks; more precisely, the lack of studies of user satisfaction highlights the need to determine the perceived value of satisfaction that the three virtual social networks (Facebook, Twitter, and Instagram) give to their users.

To be more specific, items that can measure satisfaction with the use of virtual social networks and verify their degree of importance are proposed from a review of the existing literature, determining for each of the social networks chosen whether users perceive these features to a degree that approaches the desired one, with the possible moderating elements of gender and age.

\section{Review of the literature}

\subsection{Virtual social networks}

There are few studies regarding the features of virtual social networks; aspects related to five items of great importance to their users are proposed. The first, interactivity, is defined as an extensive expression in a series of communication exchanges between users, which means that the last message is related to previous messages that are in turn related to other previous messages (Rafaeli, 1988), generating a horizontal flow of information that involves all the members of the network in the process (Cebrián-Herreros, 2008). The second, the customization or manageability of a customer profile for each user, allows users to manage the direct action on their information. The third, multimediality, allows users to be both transmitters and receivers of information, which can apply to images, audio, video, or 3-D models (Caldevilla-Dominguez, 2010). Finally, there are two factors or features that are currently being hotly debated and highly rated by users. The first is the basic characteristic of privacy confidence in the Internet, related in several studies as directly affecting the attitude towards Internet use to make purchases (Bonera, 2011) and 
closely linked to the handling of confidential information and the security level, the mechanisms of protection against potential risks, and identity theft, among others (Kim, Ferrin, and Rao, 2008; Corbitt, et al 2003). The other factor is regulations, which concern the control of access to and use of virtual social networks by private companies without clear legislation setting the rules and in many cases violating rights or other freedoms, allowing the misuse of information by users, one of the issues that is increasingly being debated among the public (Cebrián-Herreros, 2008).

\subsection{Satisfaction with the use of virtual social networks}

In the analysis of consumer behaviour, evaluating the perceptions of customers to measure satisfaction is a widely accepted method in the literature (Erevelles and Leavitt, 1992; Oliver, 1993; Oliver and Desarbo, 1988; Tse and Wilton, 1990), taking satisfaction as an emotional response to the transactional consumer experience with an organization (Oliver, 1993), in which users who experience, perceive, use, or consume products and therefore are able to assess them are the most relevant.

The study of satisfaction with SNSs is linked to the new study of Web 2.0, currently containing very little literature to date; however, to begin to relate the features of personalization and its positive influence on satisfaction (Park, 2014), other studies cited by Chan et al. (2014) highlight attributes linked to multimediality, like the fun offered by some SNSs or power generating multimedia content by users' virtual social networks. Likewise, these authors, in their study, show that there are differences between men and women regarding the elements that generate satisfaction in the use of social networks; for example, men tend to evaluate those actions that offer them entertainment (games or videos) better, while women prefer those that enable them to have better personal relationships (chat or instant messenger).

Therefore, the following hypotheses are proposed:

H1: Users prefer those virtual social networks that enable them to have high levels of customization, interactivity, multimedia, and privacy and a low level of regulation.

H2: Users of social networks have different perceptions of satisfaction with these aspects depending on their sex or age.

H3: The virtual social network with higher levels of user satisfaction is one for which the feature set of customization, interactivity, multimediality, privacy, and regulations is perceived by its users as the closest to the ideal of their virtual communication needs. 


\section{Methodology and data analysis}

\subsection{Sample and fieldwork}

To determine the questionnaire items, the concepts that several authors consider to be the most important features of a virtual social network (Table 1) were used.

Table 1. Questionnaire items

\begin{tabular}{ll}
\hline Items & References in the Literature \\
\hline $\begin{array}{l}\text { (I) Interactivity } \\
\text { I wish my social network to allow me to interact with my friends/ } \\
\text { colleagues quickly, easily, and effectively. }\end{array}$ & Caldevilla-Domínguez (2010) \\
\hline $\begin{array}{l}\text { (C) Customization } \\
\text { I wish my social network to allow me to have complete control over } \\
\text { the information made public (receive, post, note, sharing, etc.). }\end{array}$ & Park (2014) \\
\hline $\begin{array}{l}\text { (M) Multimediality } \\
\begin{array}{l}\text { I wish my social network to allow me to create and edit content, } \\
\text { text, images, or other formats instantly. }\end{array}\end{array}$ \\
\hline $\begin{array}{l}\text { (R) Regulations } \\
\text { I wish my social network to have clear and consistent legal rules } \\
\text { with my rights and freedom of expression that frame the law. }\end{array}$ \\
\hline $\begin{array}{l}\text { (P) Privacy } \\
\text { I would like to protect my social network, keep all my information (2010) } \\
\begin{array}{l}\text { secure, and have confidential protection mechanisms with verifiable } \\
\text { data. }\end{array}\end{array}$ \\
\hline
\end{tabular}

Source: Authors.

The concepts were measured on a Likert scale from 0 to 10 , which is best suited to quantifying qualitative perceptions (Churchill and Lacobucci, 2002).

The study population consisted of users of the social networks Facebook, Instagram, and Twitter; the fieldwork was conducted using a form posted on the Internet, which was spread using social networks in countries in Latin America. The selection method was random sample by quota, seeking to reach similar amounts by gender and age, but it failed to obtain information from all the target population; since children aged under 18 could not participate in the survey, this age range was omitted from the study. The data collection was conducted in March 2015, attaining a sample of 111 questionnaires, of which 11 contained flaws or problems, leaving 100 valid questionnaires for analysis (Table 2). 
The perception of satisfaction with virtual social networks: A comparative analysis 135

Table 2. Technical details of the study

\begin{tabular}{ll}
\hline Target population & $\begin{array}{l}\text { Men and women using the social networks Facebook, Twitter, and } \\
\text { Instagram }\end{array}$ \\
\hline Final sample & 100 people \\
\hline Sampling type & Quota; data collection via online form to comply with the requirement \\
& for $50 \%$ of male and $50 \%$ of female respondents \\
\hline Ages Profiles & $<18$ years: $0 \%$ \\
& $18-29$ years: $50 \%$ \\
& $>40$ years: $15 \%$ \\
\hline Countries surveyed & Colombia, Spain, Ecuador, Venezuela, Argentina, México, Costa Rica \\
\hline
\end{tabular}

Source: Authors.

\subsection{Data analysis}

The methodology used for the analysis of the data is novel; the data were analysed with the Hamming algorithm (WHD), which is a tool used as an alternative for decision making that compares results between the optimal measure as a benchmark and alternative elements by analysing their distance (Merigó and Casanovas, 2010). It is used in several related studies to select individuals, elements, or options (Figueira et al., 2005; Gil Aluja, 1999; Zavadskas and Turskis, 2011, cited by Merigó, 2013) and is applied to recruitment in the study by Gil-Lafuente (2001). The details follow:

Consider two fuzzy subsets:

$$
\begin{aligned}
& \underline{\mathrm{D}}=\left(\mu_{3} \ldots \mu_{n}\right) \\
& \underline{\mathrm{P}} \mathrm{j}=\left(\mu_{3}{ }^{(j)} \cdots \mu_{n}{ }^{(j)}\right)
\end{aligned}
$$

The distance will be:

$$
\operatorname{WHD}(\underline{\mathrm{D}}, \underline{\mathrm{P}})=\frac{1}{n} \sum_{i=1}^{n}\left|\mu_{i}-\mu_{i}^{(j)}\right|=\frac{1}{n}|| \mu_{1}-\mu_{1}^{(j)}|+| \mu_{2}-\mu_{2}^{(j)}|+\ldots+| \mu_{n}-\mu_{n}{ }^{(j)} \|
$$

The analysis process requires at least one set of optimal values and a set of other values to measure, both elected by a group of experts in relation to the decision under consideration; in addition, these values must be standardized, that is, they are taken or measured following a unified rule that states the value from 0 to 1 (Merigó, 2013).

Therefore, users of social networks assessed five features that are desirable for a virtual social network to determine the basis of subjective measurement of the same parameter and evaluation of continued satisfaction with each of the three virtual 
social networks chosen to achieve compliance with the established methodological requirements.

\subsubsection{Estimate of averages and establishment of fuzzy subsets}

The data were analysed using the SPSS computer program, obtaining the means for each item; then, the data were divided into four fuzzy subsets, the first being the assessment of importance that users give to the desired features of virtual social networks, the fuzzy subset D (Desire), then three fuzzy subsets that are the user ratings given to each of the chosen social networks: PF (Facebook), PI (Instagram), and PT (Twitter) (Tables 3-8).

Table 3. Global averages

\begin{tabular}{lccccc}
\hline social network & Interactivity & Customization & Multimediality & Regulations & Privacy \\
\hline$\underline{\mathbf{D}}$ & 0,931 & 0,926 & 0,901 & 0,936 & 0,955 \\
\hline$\underline{\mathbf{P}}$ Facebook & 0,848 & 0,731 & 0,743 & 0,589 & 0,492 \\
\hline$\underline{\mathbf{P}}$ Instagram & 0,627 & 0,695 & 0,705 & 0,653 & 0,644 \\
\hline$\underline{\mathbf{P}}$ Twitter & 0,740 & 0,722 & 0,722 & 0,684 & 0,575 \\
\hline
\end{tabular}

Authors.

Table 4. Averages by gender (women)

\begin{tabular}{lccccc}
\hline social network & Interactivity & Customization & Multimediality & Regulations & Privacy \\
\hline$\underline{\mathbf{D}}$ & 0,930 & 0,925 & 0,900 & 0,935 & 0,958 \\
\hline$\underline{\mathbf{P}}$ Facebook & 0,857 & 0,735 & 0,746 & 0,585 & 0,490 \\
\hline$\underline{\mathbf{P}}$ Instagram & 0,623 & 0,693 & 0,708 & 0,650 & 0,638 \\
\hline$\underline{\mathbf{P}}$ Twitter & 0,738 & 0,721 & 0,719 & 0,678 & 0,738 \\
\hline
\end{tabular}

Authors.

Table 5. Averages by gender (men)

\begin{tabular}{lccccc}
\hline social network & Interactivity & Customization & Multimediality & Regulations & Privacy \\
\hline$\underline{\mathbf{D}}$ & 0,931 & 0,926 & 0,901 & 0,936 & 0,955 \\
\hline$\underline{\mathbf{P}}$ Facebook & 0,848 & 0,731 & 0,743 & 0,589 & 0,492 \\
\hline$\underline{\mathbf{P}}$ Instagram & 0,627 & 0,695 & 0,705 & 0,653 & 0,644 \\
\hline$\underline{\mathbf{P}}$ Twitter & 0,740 & 0,722 & 0,722 & 0,684 & 0,575 \\
\hline
\end{tabular}

Authors. 
The perception of satisfaction with virtual social networks: A comparative analysis 137

Table 6. Averages by rank age (18-29 years)

\begin{tabular}{lccccc}
\hline social network & Interactivity & Customization & Multimediality & Regulations & Privacy \\
\hline$\underline{\mathbf{D}}$ & 0,930 & 0,924 & 0,900 & 0,937 & 0,958 \\
\hline$\underline{\mathbf{P}}$ Facebook & 0,853 & 0,729 & 0,748 & 0,578 & 0,481 \\
\hline$\underline{\mathbf{P}}$ Instagram & 0,623 & 0,693 & 0,708 & 0,647 & 0,639 \\
\hline$\underline{\mathbf{P}}$ Twitter & 0,743 & 0,726 & 0,721 & 0,678 & 0,743 \\
\hline
\end{tabular}

Authors.

Table 7. Averages by rank (30-39 years)

\begin{tabular}{lccccc}
\hline social network & Interactivity & Customization & Multimediality & Regulations & Privacy \\
\hline$\underline{\mathbf{D}}$ & 0,935 & 0,931 & 0,915 & 0,938 & 0,962 \\
\hline$\underline{\mathbf{P}}$ Facebook & 0,848 & 0,726 & 0,762 & 0,593 & 0,504 \\
\hline$\underline{\mathbf{P}}$ Instagram & 0,632 & 0,691 & 0,717 & 0,657 & 0,642 \\
\hline$\underline{\mathbf{P}}$ Twitter & 0,751 & 0,736 & 0,737 & 0,686 & 0,577 \\
\hline
\end{tabular}

Authors.

Table 8 . Averages by rank age (more than 40 years)

\begin{tabular}{lccccc}
\hline social network & Interactivity & Customization & Multimediality & Regulations & Privacy \\
\hline$\underline{\mathbf{D}}$ & 0,931 & 0,926 & 0,901 & 0,936 & 0,955 \\
\hline$\underline{\mathbf{P}}$ Facebook & 0,849 & 0,731 & 0,742 & 0,588 & 0,491 \\
\hline$\underline{\mathbf{P}}$ Instagram & 0,627 & 0,696 & 0,709 & 0,653 & 0,643 \\
\hline$\underline{\mathbf{P}}$ Twitter & 0,741 & 0,724 & 0,721 & 0,683 & 0,573 \\
\hline
\end{tabular}

Authors.

\subsubsection{Analysis of distances and testing of the moderator effect}

We proceed with the calculation of the Hamming relative distance between the desired virtual social network and each of the evaluated social networks, carried out generally and after taking into account the two control variables chosen (gender and age) (Tables 9-14).

As the final result, it is thus determined using the Hamming distance that the SNS that comes closest to the optimum sought by its users is Twitter, followed by Facebook and Instagram across the board, but the furthest from the ideal privacy and regulations is clearly Facebook (Figure 1). 
Table 9. Global Hamming Distance

\begin{tabular}{lcccccc}
\hline $\begin{array}{c}\text { social } \\
\text { network }\end{array}$ & Totals & Interactivity & $\begin{array}{c}\text { Customi- } \\
\text { zation }\end{array}$ & $\begin{array}{c}\text { Multime- } \\
\text { diality }\end{array}$ & Regulations & Privacy \\
\hline$\underline{\mathbf{P}}$ Facebook & $\mathbf{0 , 2 5 ^ { * }}$ & 0,08 & 0,20 & 0,16 & 0,35 & 0,46 \\
\hline$\underline{\mathbf{P}}$ Instagram & $\mathbf{0 , 2 7 ^ { * }}$ & 0,30 & 0,23 & 0,20 & 0,28 & 0,31 \\
\hline$\underline{\mathbf{P}}$ Twitter & $\mathbf{0 , 2 4 ^ { * }}$ & 0,19 & 0,20 & 0,18 & 0,25 & 0,38 \\
\hline
\end{tabular}

" The final Hamming distance results in the following order B, D = P (Twitter), P (Facebook), P (Instagram).

Authors.

Table 10. Hamming Distance by generate (Women)

\begin{tabular}{lcccccc}
\hline $\begin{array}{c}\text { social } \\
\text { network }\end{array}$ & Totals & Interactivity & $\begin{array}{c}\text { Customi- } \\
\text { zation }\end{array}$ & $\begin{array}{c}\text { Multime- } \\
\text { diality }\end{array}$ & Regulations & Privacy \\
\hline$\underline{\mathbf{P} \text { Facebook }}$ & $\mathbf{0 , 2 5}$ & 0,07 & 0,19 & 0,15 & 0,35 & 0,47 \\
\hline$\underline{\mathbf{P}}$ Instagram & $\mathbf{0 , 2 7}$ & 0,31 & 0,23 & $0,29^{* *}$ & $0,32^{* *}$ & 0,31 \\
\hline$\underline{\mathbf{P}}$ Twitter & $\mathbf{0 , 2 4}$ & 0,19 & 0,20 & 0,18 & 0,26 & 0,39 \\
\hline
\end{tabular}

"* Farthest values compared to men.

Authors.

Table 11. Hamming Distance by generate (Men)

\begin{tabular}{lcccccc}
\hline $\begin{array}{c}\text { social } \\
\text { network }\end{array}$ & Totals & Interactivity & $\begin{array}{c}\text { Customi- } \\
\text { zation }\end{array}$ & $\begin{array}{c}\text { Multime- } \\
\text { diality }\end{array}$ & Regulations & Privacy \\
\hline$\underline{\mathbf{P}}$ Facebook & $\mathbf{0 , 2 5}$ & 0,08 & 0,20 & 0,16 & 0,35 & 0,46 \\
\hline$\underline{\mathbf{P}}$ Instagram & $\mathbf{0 , 2 7}$ & 0,30 & 0,23 & 0,20 & 0,28 & 0,31 \\
\hline$\underline{\mathbf{P}}$ Twitter & $\mathbf{0 , 2 4}$ & 0,19 & 0,20 & 0,18 & 0,25 & 0,38 \\
\hline
\end{tabular}

Authors.

Table 12. Hamming Distance by rank age $(18-29$ years old $)$

\begin{tabular}{lcccccc}
\hline $\begin{array}{c}\text { social } \\
\text { network }\end{array}$ & Totals & Interactivity & $\begin{array}{c}\text { Customi- } \\
\text { zation }\end{array}$ & $\begin{array}{c}\text { Multime- } \\
\text { diality }\end{array}$ & Regulations & Privacy \\
\hline$\underline{\mathbf{P}}$ Facebook & $\mathbf{0 , 2 5}$ & 0,08 & 0,19 & 0,15 & 0,36 & 0,48 \\
\hline$\underline{\mathbf{P}}$ Instagram & $\mathbf{0 , 2 7}$ & 0,31 & 0,23 & 0,19 & 0,29 & 0,32 \\
\hline$\underline{\mathbf{P}}$ Twitter & $\mathbf{0 , 2 4}$ & 0,19 & 0,20 & 0,18 & 0,26 & 0,39 \\
\hline
\end{tabular}

Authors. 
The perception of satisfaction with virtual social networks: A comparative analysis 139

Table 13. Hamming Distance by rank age (30 - 39 years old $)$

\begin{tabular}{lcccccc}
\hline $\begin{array}{c}\text { social } \\
\text { network }\end{array}$ & Totals & Interactivity & $\begin{array}{c}\text { Customi- } \\
\text { zation }\end{array}$ & $\begin{array}{c}\text { Multime- } \\
\text { diality }\end{array}$ & Regulations & Privacy \\
\hline$\underline{\mathbf{P}}$ Facebook & $\mathbf{0 , 2 5}$ & 0,09 & 0,20 & 0,15 & 0,35 & 0,46 \\
\hline$\underline{\mathbf{P}}$ Instagram & $\mathbf{0 , 2 7}$ & 0,30 & 0,24 & 0,20 & 0,28 & 0,32 \\
\hline$\underline{\mathbf{P}}$ Twitter & $\mathbf{0 , 2 4}$ & 0,18 & 0,20 & 0,18 & 0,25 & 0,39 \\
\hline
\end{tabular}

Authors.

Table 14. Hamming Distance by rank age (more than 40 years)

\begin{tabular}{lcccccc}
\hline $\begin{array}{c}\text { social } \\
\text { network }\end{array}$ & Totals & Interactivity & $\begin{array}{c}\text { Customi- } \\
\text { zation }\end{array}$ & $\begin{array}{c}\text { Multime- } \\
\text { diality }\end{array}$ & Regulations & Privacy \\
\hline$\underline{\mathbf{P}}$ Facebook & $\mathbf{0 , 2 5}$ & 0,08 & 0,20 & 0,16 & 0,35 & 0,46 \\
\hline$\underline{\mathbf{P}}$ Instagram & $\mathbf{0 , 2 6}$ & 0,30 & 0,23 & 0,19 & 0,28 & 0,31 \\
\hline$\underline{\mathbf{P}}$ Twitter & $\mathbf{0 , 2 4}$ & 0,19 & 0,20 & 0,18 & 0,25 & 0,38 \\
\hline
\end{tabular}

Authors.

Figure 1. Hamming distances for Facebook, Twitter and Instagram about the SNSs optimized

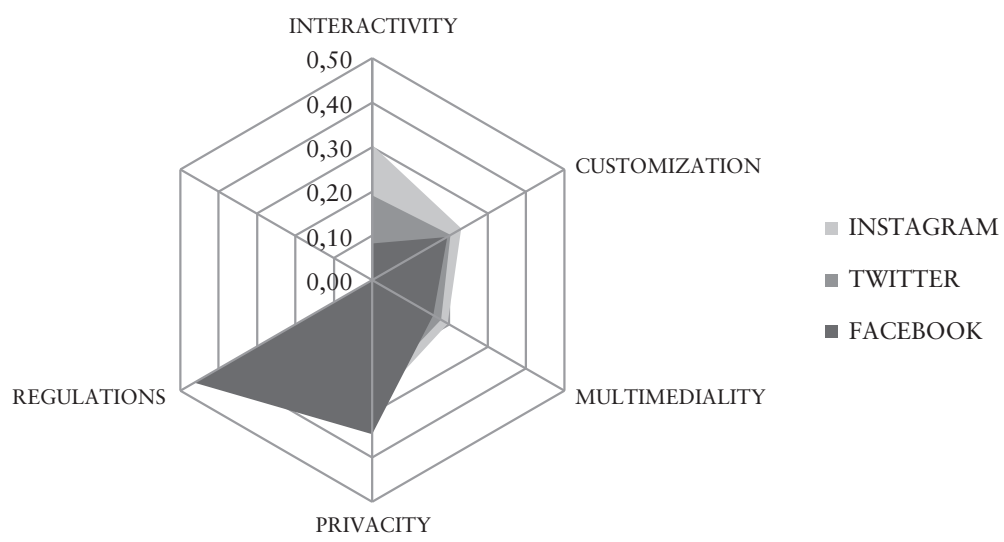

Authors.

\section{Results and Conclusions}

The analysis of Hamming distances allowed us to validate hypothesis 1, that is, users seek virtual social networks that allow them to have high levels of 
customization, interactivity, multimedia, and privacy and low levels of standards. The higher averages of 9 out of 10 (Table 3 ) note the importance of these features in meeting the communication needs and uses of both men and women (Tables 10 and 11) and all the age ranges studied (Tables 12-14). This also serves as the first element of verification opposing hypothesis 2 , that is, that these needs differ by age or gender, similarly to the study by Espinar-Ruiz and Gonzalez-Rio (2009), in which no big differences are found between boys and girls in the use of virtual social networks.

However, as regards the satisfaction of these needs by the three virtual social networks, firstly Facebook produces a great contrast, having the closest distances in three indicators related to the ease of communication within the network: customization $(0.20)$, multimediality $(0.16)$, and the closest, the factor of interactivity (0.08). Conversely, regulations $(0.35)$ and privacy $(0.46)$ are the greatest distances from the ideal. The latter is the furthest distance from the ideal of the three virtual social networks chosen (Table 9).

The reverse case is Instagram, a virtual social network that is limited to pictures and short videos, for which the distances for customization (0.23), multimediality $(0.20)$, and interactivity $(0.30)$ are greater than those of Facebook. Therefore, more dissatisfaction is generated for its users in relation to these points. However, its regulations (0.28) and privacy (0.31) are closer to the ideal than those of Facebook (Table 9).

Finally, hypothesis 3 is confirmed. Compared with Facebook or Instagram, Twitter displays Hamming distances that are more balanced in all the measured features, the smallest Hamming distance being 0.24 (Figure 1), and therefore it is found that the virtual social network with the highest levels of user satisfaction concerning the set of considered features is Twitter. This is the virtual social network among the three that best meets users' requirements regarding customization $(0.20)$, interactivity (0.19), multimediality (0.18), privacy (0.38), and regulations (0.25) (Table 9).

It has been shown that satisfaction with the use of social networks can be measured in ways that bring together many features discussed in other studies that have allowed users to verify their importance to the development of the 3.0 Internet, in which interactivity, customization, and multimediality dominate the future of social relationships (Figure 1).

Finally, the issues of privacy and social networking regulations demonstrate the concern of users regarding the handling of information, highlighting not only users as potential victims of its misuse, but also their freedoms and rights as generators of content and showing that social networks have full control until the information is circulated and therefore this key role is becoming increasingly controversial and debated in various political, social, and legal scenarios.

This study suffers from several limitations, among which are the selection and grouping of a set of features that were evaluated separately, so no previous references to other models that measure satisfaction with virtual social networks globally were taken; likewise, although a scanning mechanism was primarily used, this study did not intend to examine directly whether users prefer one network to another, rather allowing users to rate the service obtained from each of them. 
The sample size limitations presented are considered to be small, but it is worth noting that the results show little variability and therefore are suitable, but further study is needed to compare the results; following these parameters, the assessment of users aged under 18 is lacking, and this is the generation that is growing up accustomed to using the Internet and understanding the concepts of these social networks.

This article may serve as a precedent for the study of new communication tools through new technology and the study of the needs of cyber-virtual users not only for social networking, but also for those companies that provide web services, such as email, virtual communities, or blogs, which identify customer needs and satisfaction as being of great value.

\section{References}

Bonera, M., 2011, The propensity of e-commerce usage: the influencing variables. Management Research Review, 34(7), 821-837.

Caldevilla-Dominguez, D., 2010, Las redes sociales. Tipología, uso y consumo de las redes 2.0 en la sociedad digital actual. Documentacion de las Cliencias de la Información. 33. 45-68.

Cebrian-Herreros, M., 2008, La web 2.0 como red social de comunicación e información. Estudios sobre el Mensaje Periodistico. 14, 345-361.

Corbitt, B. J., Thanasankit, T. and Yi, H., 2003, Trust and e-commerce: a study of consumer perceptions. Electronic Commerce Research and Applications, 2, 203-215.

Chan, T., Cheung, C., Shi, N. and Lee, M., 2014, Gender differences in satisfaction with Facebook users. Industrial Management \& Data Systems. 115 (1). 182-206.

Churchill, G. A. and Lacobucci, D., 2002, Marketing research metodological foundations (8tb ed.). Mason; Thomson.

Erevelles, S. and Leavitt, C., 1992, A comparison of current models of consumer satisfaction/dissatisfaction. Journal of Consumer Satisfaction, Dissatisfaction \& Complaining Behaivor. 5(10). 104-114.

Escobar-Rodríguez, T. and Carvajal-Trujillo, E., 2014, Online purchasing tickets for low cost carriers: An application of the unified theory of acceptance and use of technology (UTAUT) model. Tourism Management, 43, 70-88.

Gil-Lafuente, J., 2001, The index of maximum and minimum level in the selection of players in sport management (in Spanish), in: Proceedings of 10th International Conference of the European Academy of Management and Business Economics (AEDEM), Reggio Calabria, Italy, pp. 439-443.

Merigo, J., 2013, The probabilistic weighted averaging distance and its application in group decisión making. Kybernetes. 42 (5). 686-697.

Merigo, J. and Casanovas, M., 2010, Decision making whit distance measures and lnguistic aggregation operators. International Journal of Fuzzy Systems. 12 (3). 190-198. 
Kim, D. J., Ferrin, D. L. and Rao, H. R., 2008, A trust-based consumer decision-making model in electronic commerce: The role of trust, perceived risk, and their antecedents. Decision Support Systems, 44, 544-564.

Oliver, R. L., 1993, A conceptual model of service quality and service satisfaction compatible goals, different concepts. Advances in Services Marketing and Management, 2, 65-68.

Oliver, R. L. and Desarbo, W. S., 1988, Response determinants in satisfaction judgments. Journal of Consumer Research. 14. 495-507.

Park, J., 2014, The effects of personalization on user continuance in social networking sites. Information processing and Management. 50. 462-475.

Parra-Castrillón, E., 2010, Las redes sociales de Internet: también dentro de los hábitos de los estudiantes universitarios. Anagramas, 9 (17), 107-116.

Rafaeli, S., 1988, Interactivity: From new media to communication. Sage Annual Review of Communication Research: Advancing Communication Science. 16, 110-134.

Tse, D.K. and Wilton, P.C., 1988, Models of consumer satistaction formation: and extensive. Journal of Marketing research. 25 (2). 86-97. 
The perception of satisfaction with virtual social networks: A comparative analysis 143

\section{Notes on Contributors}

Name: Javier A. Sánchez Torres

University: Universitat de Barcelona

Address: Av. Diagonal, 690. 08034 Barcelona

Email: jsanchto19.alumnes@ub.edu

Name: Francisco-Javier Arroyo-Cañada

Position: Professor

School / Faculty: Departamento de Economía i Organización de Empresas

University: Universitat de Barcelona

Address: Av. Diagonal, 690. 08034 Barcelona

Email: fjarroyo@ub.edu 